TEMAS EMERGENTES

\title{
Constitucionalismo global y derechos humanos
}

\author{
Global constitutionalism and human rights
}

\author{
Angello Javier Peña Barrios \\ Universidad de Los Andes, Venezuela
}

\begin{abstract}
RESUMEN El presente artículo analiza la noción de constitucionalismo global y su relación con los derechos humanos. En primer lugar, estudia el concepto de soberanía y cómo cambió, especialmente después de la Segunda Guerra Mundial, para señalar que en la actualidad tiene un significado distinto. En segundo lugar, se refiere a conceptos acerca del constitucionalismo clásico y social, abordando su surgimiento y los derechos creados para cada momento histórico. En tercer lugar, señala la necesidad de pensar un constitucionalismo global a partir de los problemas globales que afronta la humanidad, la constitucionalización del derecho internacional de los derechos humanos y el ius cogens como conjunto de normas inderogables para los países que componen la comunidad internacional. Finalmente, indica el lugar que ocupan los derechos humanos en el constitucionalismo global, como el motor que impulsa la idea universal de constitución como orden jurídico supraestatal.
\end{abstract}

PALABRAS CLAVE Estado, derecho constitucional, globalización, constitución, soberanía.

ABSTRACT This paper analyzes the concept of global constitutionalism and its relationship with human rights. Firstly, it studies the concept of sovereignty and how it changed after the Second World War, to point out sovereignty does have a different meaning currently. Secondly, it refers to concepts of traditional and social constitutionalism studying how they were created for each historical moment. Thirdly, it studies the need of thinking on a global constitutionalism from global problems humanity faces, the constitutionalization of International Law of Human Rights and the ius cogens as peremptory norms to countries of the international community. Finally, it refers to the place of human rights in global constitutionalism being the engine that drives the universal idea of constitution as supra-state legal order.

KEYWORDS State, constitutional law, globalization, constitution, sovereignty. 


\section{Introducción}

Se encuentra en el pensamiento contemporáneo del constitucionalismo una especie de percepción amplia y universal sobre la idea de constitución, en específico, con relación a los derechos humanos. Se observa en la doctrina constitucional denominaciones de constitucionalismo como "global» (Ferrajoli, 2018a: 41), "cosmopolita» (Somek, 2014: 2) o «posnacional» (Walker, 2016: 309), que pretenden ir más allá de las ideas clásicas de soberanía y constitucionalismo, y se apoyan en argumentos que implican, si no una crisis del Estado nacional, sí su transformación en el panorama que propone la actualidad de las complejidades sociales.

Gran parte de los problemas a los cuales se enfrenta la humanidad superan las barreras del Estado nacional. Son problemas que tienen un margen amplísimo, como pueden ser, por ejemplo, las migraciones, el calentamiento global, la guerra, el terrorismo, los crímenes de lesa humanidad o los riesgos del uso de la energía atómica y las nuevas tecnologías sin ningún parámetro normativo. Son temas que no pasan desapercibidos en la agenda política de múltiples países. Pareciera que los fenómenos de esa índole no pueden ser resueltos desde el espacio reducido de los Estados tradicionales y sus constituciones nacionales. Especialmente el caso del medio ambiente, con el aire o el agua como bienes jurídicos universales, permitiría pensar en esa posibilidad. Si los problemas a los que se enfrenta la humanidad son globales, entonces las soluciones micro, pensadas localmente dentro de determinadas fronteras nacionales, resultan insuficientes. Se hace indispensable pensar globalmente, para lo cual, es pertinente desde el plano académico preguntarse por el constitucionalismo global y sus posibilidades a través del concepto de los derechos humanos.

En ese orden, la presente investigación tiene como objetivo analizar la noción de constitucionalismo global con respecto a los derechos humanos, ${ }^{1}$ para interpretar el rol que cumplen los derechos en tal postura del constitucionalismo. Esto se cumplirá a partir de los conceptos de soberanía, constitucionalismo y derechos humanos, que se encuentran en gran parte relacionados. Se enmarca en una investigación dogmática constitucional con un diseño de tipo descriptivo y documental que emplea como fuente principal la doctrina.

\section{La transformación de la soberanía}

\section{El asentamiento de la soberanía popular}

El concepto de soberanía en sentido clásico se manifestó como el poder de autodeterminación del Estado, la voluntad de autodirigirse a través de las normas jurídicas

1. Se entienden las diferencias que existen entre derechos humanos, derechos fundamentales y derechos constitucionales. Sin embargo, a lo largo de este trabajo se usarán indistintamente. 
o, como señala Jellinek (2004: 438), «la propiedad del poder de un Estado, en virtud de la cual corresponde exclusivamente a este la capacidad de determinarse jurídicamente y de obligarse a sí mismo». Esta es la percepción clásica de soberanía pensada por Bodino y Hobbes (siglos XVI y XVII), cuya titularidad inicial correspondía a un sujeto con poderes absolutos o a quien tuviera en sus manos el poder ejecutivo en la organización política. Posteriormente, con aportes de pensadores como Rousseau a través de su contrato social, vendría a introducir en esta pugna conceptual sobre la titularidad de la soberanía, un ingrediente fundamental como lo es la voluntad general o popular. De hecho, el concepto de soberanía popular fue tomado en la Constitución federal de 1787 en los Estados Unidos de Norteamérica, «we the people», como consecuencia de la Revolución norteamericana. Otro importante elemento a considerar es la Revolución francesa, que tuvo como fruto la Declaración de Derechos del Hombre y del Ciudadano de 1789 y, además, en la Constitución francesa de 1791 y posteriores constituciones revolucionarias de ese país, en las cuales se incorporó el concepto de soberanía nacional, pensado por el abate Sieyés.

Desde la etapa moderna, el concepto de soberanía es atribuido al pueblo o a la nación - que a la postre vienen a ser lo mismo- como resultado de los pensadores políticos de la Ilustración. Así, la soberanía clásica u originaria se entendía como el poder estatal de garantizar su primacía e inalienabilidad en la esfera política, ante competidores internos que se encontraban sometidos a su disposición y a lo externo mediante sus relaciones por medio del principio de no intervención (Zagrebelsky, 2011: 10). En la actualidad, existe consenso en los Estados constitucionales acerca de que la titularidad de la soberanía le pertenece a las personas en su generalidad, sin discriminación alguna. Según Ferrajoli, soberanía popular es un homenaje verbal al carácter democrático representativo de los sistemas políticos contemporáneos ( $\mathrm{Fe}$ rrajoli, 1998: 174). De allí que, para De Vega (2007: 49), «nadie, al menos a nivel propagandístico y retórico, se atreve a poner en duda que el pueblo es el único titular de la soberanía». Así, la soberanía popular es un principio de la política constitucional prácticamente aceptado.

\section{La erosión del carácter absoluto de la soberanía popular}

Se suele señalar en la literatura que en los Estados constitucionales no cabrían poderes absolutos, ni siquiera los de la mayoría, que en no pocas oportunidades han puesto en peligro los derechos de todos - tanto de las propias mayorías, como especialmente las minorías-. Eso, por cuanto se ha desvanecido la potestas legibus soluta del Estado clásico (Ferrajoli, 2011: 36) y nadie puede ser o decidir por todos en lo que concierne a todos en un Rechstaat democrático (O’Donell, 2004: 20). La noción de soberanía, como sostiene Zagreblesky (2011: 11-12), 
no puede reconocerse con aquella claridad como realidad política operante. Desde finales del siglo pasado actúan vigorosamente fuerzas corrosivas, tanto interna como externamente: el pluralismo político y social interno, que se opone a la idea misma de soberanía, aunado [...] con la idea de atribución de derechos a los individuos, que pueden hacerlos valer ante jurisdicciones internacionales frente a los Estados a que pertenecen.

En ese sentido, para Ferrajoli (1998: 174), en las democracias constitucionales no existen ya los poderes o sujetos absolutos y soberanos. La soberanía tanto interna como externa de los Estados habría sufrido una transformación con el auge de los derechos humanos. Eso claramente viene reforzado después de la mitad del siglo XX con la reflexión inherente al menoscabo de la dignidad humana por los totalitarismos del fascismo y nazismo. Así, si bien existen diversos factores que erosionan la noción de soberanía, lo que interesa aquí destacar es el referido a los derechos humanos. En efecto, los derechos humanos constituyen uno de los factores demoledores de la soberanía (Zagrebelsky, 2011: 12). Autores como Grimm (2015: 124) indican que el concepto de soberanía está desapareciendo. En esta misma línea, García-Pelayo advirtió ya en 1977 que «el Estado ha perdido su capacidad de autodeterminación, no representa lo general-concreto, es algo que está extensivamente más allá e intensivamente más acá de su concepto clásico» (García-Pelayo, 1977: 181). El Estado está en una etapa de transformación de su aspecto tradicional, en la cual incide en gran proporción la dimensión de los derechos humanos y sus implicaciones.

\section{La dimensión de los derechos en el constitucionalismo clásico y social}

\section{Constitucionalismo clásico}

El constitucionalismo de lo que se puede denominar como clásico es el que vino de la mano con el surgimiento del Estado nacional. Es una noción que pertenece por entero a la Edad Moderna (Fioravanti, 2014: 142). La noción tradicional de constitucionalismo fue creada por la imaginación de pensadores políticos de vanguardia, cuyas ideas resultaron muy relevantes para su momento, e incluso aún conservan una gran importancia cuando se reflexiona sobre los diseños institucionales. Tales son los casos de Montesquieu con El espíritu de las leyes, Locke con Dos tratados sobre el gobierno civil, Rousseau con El contrato social, Paine con Los derechos del hombre, o Hamilton, Madison y Jay con El federalista. Este constitucionalismo, que sentó las bases de cómo limitar el Leviatán, surgió fundamentalmente de las revoluciones liberales del siglo XVIII, cuando se efectuaron procesos de lucha por los derechos civiles y políticos y la división y equilibrio del poder político.

El constitucionalismo de los clásicos, como es de esperar, fue un constitucionalismo limitado. Limitado en el sentido de que apenas nace el cuerpo político insti- 
tucionalizado y se busca racionalizar su poder. El constitucionalismo se convirtió en una consigna política para aquellos que querían que se desarrollase o se estableciese un nuevo orden jurídico y político más acorde con los tiempos (Dippel, 2009: 15). En efecto, el objetivo central de las revoluciones que pujaron en contra del absolutismo era la elaboración de una constitución (Arendt, 2006: 176).

Se destaca de este constitucionalismo la preocupación por controlar el poder y racionalizarlo, para así proteger los derechos fundamentales de índole liberal como la libertad de expresión, la libertad personal y la propiedad privada. Los elementos orgánicos de las primeras constituciones escritas, tanto de la corriente norteamericana como europea - por ejemplo, la Constitución norteamericana de 1787 o la Constitución francesa de 1791-, contaban con un modelo de división y equilibrio del poder, que era la forma de garantizar la libertad.

Por ejemplo, para Montesquieu, cuando todos los poderes «se reúnen en la misma persona o el mismo cuerpo de magistrados, no hay libertad, porque puede temerse que el monarca o el tirano haga leyes tiránicas para ejecutarlas tiránicamente» y «no hay tampoco libertad si el Poder Judicial no está separado del Legislativo y el Ejecutivo» (Montesquieu, 1986: 227). Para los clásicos, cuando no existía separación de poderes, era casi inevitable la injusticia y la arbitrariedad del poder. Por ende, se teorizó incluso el derecho a la rebelión como un derecho fundamental. Asimismo, si bien existieron declaraciones de derechos como la Declaración de Derechos inglesa de 1688, la prestigiosa Declaración de los Derechos del Hombre y del Ciudadano de 1789, o las diez primeras enmiendas de la Constitución Federal de los Estados Unidos de 1791, tales declaraciones solo fueron suficientes para ese primer tiempo de la sociedad, porque fungían como obligaciones de no hacer para el Estado. Por consiguiente, el Estado se veía limitado a interferir en la esfera individual de la persona.

\section{Constitucionalismo social}

Con el avance de las sociedades civiles y fenómenos como la Revolución Industrial surgieron nuevas necesidades para las cuales el constitucionalismo clásico no era suficiente. En efecto, las instituciones y derechos que pregonaba el constitucionalismo tradicional no cumplían con las expectativas de las nuevas ideas y necesidades que requería la sociedad, por lo que se hizo necesario reformar el constitucionalismo. Desde finales del siglo XIX, con la incorporación en el proceso político de una nueva clase social representada políticamente por los partidos obreros y los partidos socialistas, el Estado experimentaría un cambio notable (Pérez, 2003: 202). Igualmente, es de resaltar que la exigencia de los derechos sociales y su reconocimiento jurídico suelen reclutar partidarios entre quienes poseen una sensibilidad igualitaria (Pisarello, 2007: 11-12). Es razonable que sea así. De hecho, Ferrajoli (2007: 75) denomina a los derechos sociales como leyes del más débil, cuyo fundamento es la supervivencia 
contra la ley de quien es más fuerte social y económicamente.

La necesidad de agregar nuevas ideas al constitucionalismo se empezó a denotar pronto en importantes documentos políticos del siglo XX, porque precisamente hubo un cuestionamiento en el ámbito de los movimientos socialistas (Neves, 2004: 163). Pensadores de esa época como Karl Marx criticaron al capitalismo señalando la forma en que las personas son explotadas, y entregaron propuestas sobre cómo deberían organizarse las sociedades, sobre todo en lo concerniente al trabajo. Fue una nueva forma de pensar y de desenvolvimiento de las nuevas relaciones sociales, lo que promovió la teorización política de nuevos derechos que tienen como fundamento ya no esencialmente la libertad, sino la igualdad de las personas. Tal sería el caso específico de derechos a «la jornada de trabajo, a la asociación y a la educación» (Atienza, 1982: 26). Derechos pensados para garantizar la «procura existencial» que en su momento señaló Ernest Forsthoff.

La constitucionalización de nuevas exigencias de la sociedad se denotó con la Constitución Política de los Estados Unidos de México (1917), la Declaración de los Derechos del Pueblo Trabajador y Explotado (1918), la Constitución de la Organización Internacional del Trabajo (1919) y la Constitución de Weimar (1919). Tales textos introdujeron nuevos paradigmas sobre los derechos humanos, los cuales cumplen, según esta concepción, una función social, en que existe «un rechazo de una visión unilateral de los derechos individuales de libertad y, con mayor razón, de una concepción liberal e individualista de los derechos fundamentales» (Häberle, 2003: 11).

Entre los derechos que se establecieron en estos documentos se encuentran el derecho a la igualdad; el derecho al trabajo; el derecho a una jornada laboral de ocho horas; el derecho de asociación de los trabajadores; el derecho a la educación obligatoria, pública y gratuita; el derecho a la enseñanza laica, y la libertad sindical. Estos derechos configuraron un paso más del constitucionalismo, ya no delimitando lo que el Estado no debe hacer, sino lo que debe hacer mediante un actuar positivo. ${ }^{2}$ Con el actuar positivo del Estado se pretende asegurar condiciones de vida dignas para los grupos vulnerables. La inclusión de los derechos sociales era inevitable para el soporte del constitucionalismo.

\section{La necesidad de pensar un constitucionalismo global}

Fenómenos que azotan globalmente a los Estados como el cambio climático, la guerra, el terrorismo, la pobreza, los crímenes de lesa humanidad y las nuevas tecnologías son fuentes de graves problemas y repercuten de alguna manera en todos, aun-

2. Cabe destacar tal actuar positivo solo entendiendo como premisa básica. También existen tesis que postulan que ni todos los derechos sociales son positivos, ni todos los derechos liberales son negativos, lo cual resulta razonable. 
que en grados diferentes. Tales fenómenos son comprendidos también en lo que se denomina como sociedad del riesgo (Beck, 1998a: 15), cuyos riesgos, a diferencia de la sociedad industrial, provienen más de los seres humanos y menos de la propia naturaleza, lo que tiene graves consecuencias que llevan a replantearse desde las ciencias sociales cómo afrontarlos.

Eso ha implicado «afrontar las transformaciones que viene suponiendo para el derecho público, tanto para el derecho internacional público como para el derecho constitucional» (Jiménez, 2019: 143). En efecto, a pesar de los pasos que venía dando el constitucionalismo clásico y social, los problemas que enfrentan en este momento las sociedades requieren de soluciones que sean pensadas desde una perspectiva más amplia y no desde «los espacios restringidos de los confines nacionales» (Ferrajoli, 2018b: 129). De hecho, ni el Estado ni la percepción de constitucionalismo «son ya lo que eran» (Clavero, 2014: 131). Ahora se imagina un constitucionalismo que transforma del derecho público en general y «se expande de manera irreversible más allá de las fronteras estatales y nacionales» (Fioravanti, 2014: 156).

La política constitucional no sería suficiente si es implementada solo desde un punto de vista interno (micro), porque las afectaciones o riesgos son tanto locales y nacionales como globales; especialmente riesgos globales que imponen la necesidad de repensar las estrategias institucionales, desde una perspectiva mucho más amplia a las del pasado. Eso incluye la propia manera de pensar el constitucionalismo. Por eso resulta pertinente resaltar lo que Beck (1998b: 18) denomina como «la invención de lo político». La comunidad científica debe reflexionar sobre nuevos y hasta de viejos conceptos que pudieran ahora tener un significado distinto, incluso susceptible de ser modificado. Los problemas del mundo globalizado requieren nuevas soluciones, ya que los diseños institucionales viejos y hasta los vigentes no son suficientes. La política constitucional necesita innovar, pensar y crear. En consecuencia, el constitucionalismo parece aspirar a un ámbito global que proteja bienes jurídicos fundamentales puestos en riesgo. Reflexionar con respecto a los derechos humanos sobre la idea kantiana de «constitución cosmopolita» (Habermas, 2008: 444). Eso sí, como advierte Ferrajoli, si bien esta perspectiva del constitucionalismo "es difícil e improbable», «contrariamente al escepticismo dominante, no es en absoluto imposible» (Ferrajoli, 2018b: 133). La invención de la política constitucional tiene un rol que cumplir en esta postura para hacerla más probable y menos imposible.

\section{La constitucionalización del derecho internacional de los derechos humanos}

Una de las denominadas «tres C» del constitucionalismo global, además de constitución y constitucionalismo, es la referida al concepto de constitucionalización (Wiener Antje y otros, 2012: 4-6). De hecho, la constitucionalización de importantes esferas 
de la comunidad política es un rasgo que se identifica también con las constituciones más recientes que se han suscitado tanto Europa - conocida con la denominación de neoconstitucionalismo - como en América Latina - a la que se denomina nuevo constitucionalismo latinoamericano-. Es una tendencia de las nuevas constituciones, que buscan algo así como «una constitución invasiva, que condiciona la legislación, la jurisprudencia, la doctrina y los comportamientos de los actores políticos» (Comanducci, 2010: 175).

En ese sentido, para Guastini (2016: 153), la constitucionalización implica «un proceso de transformación de un ordenamiento, al término del cual, el ordenamiento en cuestión resulta totalmente impregnado por las normas constitucionales». Es decir, en términos más claros, no se trata de constituciones que regulan lo mínimo de la vida política en una sociedad, sino que van más allá, y en la carta constitucional se incluyen esferas que antes estaban encomendadas a la voluntad representativa y -de forma- discrecional del Poder Legislativo y, por tanto, no se encontraban estipuladas como una obligación constitucional - de hacer o de no hacer-. Ahora, por el contrario, la actividad representativa de las instituciones se encuentra en gran parte vinculada por las normas constitucionales e internacionales y las decisiones tomadas por las instituciones democráticas deben corresponderse con los principios, valores y reglas de la norma fundamental y los tratados internacionales sobre derechos humanos.

Los textos constitucionales que tomaron este proceso han incorporado cláusulas sobre el derecho internacional de los derechos humanos por la preocupación acerca de la dignidad humana. Cláusulas de este tipo son una invitación a pensar el constitucionalismo global. Esa situación claramente denota un nuevo perfil de las constituciones y del Estado, que han adquirido una mirada más internacionalista posicionándose como «abiertas al problema de las garantías frente al cumplimiento de normas internacionales». De esa manera, la entidad estatal tiene una dimensión más acentuada en el plano internacional, padeciendo algo parecido a una crisis de «doble personalidad» en cuanto a Estado de derecho y democracia concierne (Jiménez, 2019: 149).

Este fenómeno ha implicado un aumento de la actividad constitucional en muchas partes del mundo después de la Segunda Guerra Mundial, generando lo que se ha denominado como migración constitucional en conceptos, derechos y doctrinas (Shinar, 2019: 5). En efecto, a partir de las lecciones que trajo la tragedia de la Segunda Guerra Mundial, se produjo un cambio de paradigma tanto para el Estado de derecho como para la democracia, lo cual implicó el proceso de constitucionalización de los derechos humanos y la estipulación en las relaciones internacionales del principio de la paz y los derechos a través de múltiples tratados internacionales sobre derechos humanos (Ferrajoli, 2018a: 66-67). 
Casos emblemáticos son los de países ubicados en regiones como Europa ${ }^{3}$ y América Latina. ${ }^{4}$ En la región europea, la Constitución de España se refiere en su artículo 10 a «normas relativas a los derechos fundamentales y a las libertades que la Constitución reconoce se interpretarán de conformidad con la Declaración Universal de Derechos Humanos y los tratados y acuerdos internacionales sobre las mismas materias ratificados por España». La Constitución de Portugal señala en su artículo 8 que «las normas y los principios de derecho internacional general o común forman parte integrante del derecho portugués».

En el caso latinoamericano, la Constitución de Venezuela dispone en su artículo 23 que los «tratados, pactos y convenciones relativos a derechos humanos, suscritos y ratificados por Venezuela» tienen «jerarquía constitucional y prevalecen en el orden interno, en la medida en que contengan normas sobre su goce y ejercicio más favorables a las establecidas en esta Constitución y en las leyes de la República». El artículo 93 de la Constitución Política de Colombia señala que los «tratados y convenios internacionales ratificados por el Congreso, que reconocen los derechos humanos y que prohíben su limitación en los estados de excepción, prevalecen en el orden interno»; por ello, los «derechos y deberes consagrados en esta Carta, se interpretarán de conformidad con los tratados internacionales sobre derechos humanos ratificados por Colombia».

Instrumentos internacionales sobre derechos humanos, como pueden ser la Declaración Universal de Derechos Humanos de 1948, la Declaración Americana de Derechos y Deberes del Hombre igual de 1948, la Convención Europea de Derechos y Libertades de 1951, el Pacto Internacional de Derechos Civiles y Políticos y el Pacto Internacional de Derechos Económicos, Sociales y Culturales ambos de 1966, forman en su conjunto un andamiaje valioso - pero incompleto- para la protección de los derechos humanos, acogido por los Estados constitucionales.

La aceptación de tales tratados por parte de los Estados, sobre todo los universales, son «el comienzo de la constitucionalización del derecho internacional» (Peters, 2018: 6). Así, se indica que existe una dependencia entre el derecho constitucional e internacional. El Estado constitucional contemporáneo es pluralista, partiendo de una estructura abierta tanto internamente como exteriormente y residiendo aspectos de legitimidad en ambos espacios. La estructura de relaciones que enfrenta el Estado son supranacionales a partir de múltiples instituciones internacionales y la atención de los ciudadanos extranjeros, encontrándose vinculada normativamente a tratados

3. Este es el mejor caso de integración y posibilidad de ceder soberanía, con el objeto de obtener beneficios recíprocos para alcanzar metas conjuntas, como lo es la garantía de los derechos humanos.

4. Esta región, por medio de la Organización de Estados Americanos y la Comisión y Corte Interamericana de Derechos Humanos, pretende afianzar algo parecido al caso europeo. Sin embargo, tiene muchos defectos que corregir y reflexionar, pues está muy lejos todavía. 
internacionales que en algunos casos pueden producir efectos jurídicos inmediatos y la capacidad para obtener beneficios comunes supranacionalmente (Jiménez, 2019: 149).

Asimismo, como señala Ferrajoli, dar importancia a los acuerdos internacionales sobre derechos humanos - sobremanera los de alcance global- es «reconocer la embrionaria constitución global que ya existe en la Carta de Naciones Unidas y en los diversos pactos y declaraciones de derechos humanos. Implica ver la realidad desde el punto de vista de un constitucionalismo global» (Ferrajoli, 1998: 178). En otras palabras, es reconocer compromisos necesarios que se han implementado globalmente para proteger los derechos humanos, indispensables para la igualdad y libertad en la mayor parte de las sociedades.

El derecho internacional ahora penetra las fronteras del Estado y se aplica a las relaciones entre Estados y sus habitantes (Grimm, 2015: 124). Esa penetración, por la constitucionalización del derecho internacional de los derechos humanos, se aplica incluso bajo la recepción constitucional que da prioridad a las reglas e interpretaciones en pro de los derechos humanos. Así, las cláusulas de recepción de los tratados internacionales sobre derechos humanos son una invitación a pensar el constitucionalismo desde una perspectiva amplísima.

Otro aspecto importante a señalar sobre la constitucionalización en la idea de constitucionalismo global es que no se ha tomado como un proceso exclusivo de las constituciones nacionales. También se producen dinámicas de constitucionalización en «subsistemas sociales no estatales», lo que supondría serios cambios y un gran reto para la teoría constitucional (Jiménez, 2019: 162). Peters (2018: 4) reconoce esto al indicar que se producen «elementos constitucionales en el orden jurídico internacional por actores jurídicos y políticos». Esta situación podría ser favorable para el derecho internacional público, por cuanto se le atribuye que es un derecho fragmentado y la incorporación del constitucionalismo a la esfera internacional es útil para superar esas críticas y fortalecer aún más la importancia de esa disciplina, sobremanera con los derechos humanos.

\section{lus cogens y derechos humanos}

Existen, además de las normas establecidas internamente en las constituciones de los Estados, lo que en el derecho internacional público se conoce como ius cogens, un conjunto de normas de carácter público que se interpretan como inderogables para los Estados. Su incumplimiento, cuanto menos, produciría una alteración en el orden internacional y, cuanto más, puede afectar gravemente las relaciones entre los Estados y las organizaciones internacionales, produciendo en el peor de los casos escenarios bélicos. Para Sagués (2009: 153), tales normas tienen un origen «convencional o consuetudinario, más allá incluso de la voluntad de estos de cumplirlas o 
de desobedecerlas». Según Mora-Carvajal (2020: 106-107), desde el punto de vista de la validez jurídica, la importancia de estas normas es que «aguarda criterios de validez jurídica sustanciales, convirtiéndose en un límite a la voluntad soberana de los Estados y otros sujetos internacionales en la creación del derecho internacional». Destaca Jiménez (2019: 150) que las normas de ius cogens fungen como «el núcleo de una constitución internacional, componiendo un conjunto de principios supremos o constitucionales, dado su carácter de normas superiores, metanormas o normas de normas al regular la producción normativa que realizan los Estados al celebrar tratados internacionales». Las tres percepciones sobre las normas de esta índole indican que son un conjunto de preceptos fundamentales o superiores del derecho internacional público, he allí su importancia para el mantenimiento pacífico de las relaciones internacionales.

La Convención de Viena del 23 de mayo de 1969, sobre el Derecho de los Tratados, indica en su artículo 53 lo que se pudiera entender por ius cogens:

Es nulo todo tratado que, en el momento de su celebración, esté en oposición con una norma imperativa de derecho internacional general. Para los efectos de la presente Convención, una norma imperativa de derecho internacional general es una norma aceptada y reconocida por la comunidad internacional de Estados en su conjunto como norma que no admite acuerdo en contrario y que solo puede ser modificado por una norma ulterior de derecho internacional general que tenga el mismo carácter.

Según la disposición indicada en la Convención, son normas de ius cogens aquellas de carácter imperativo y general para la comunidad internacional de Estados, que inclusive van más allá de la voluntad de cumplirla. Sin embargo, no se establece con exactitud qué tipos y supuestos de normas serían, por lo que es muy vago lo señalado. Retomando la idea de la validez jurídica de las normas internacionales y su jerarquía, las normas de ius cogens constituyen un «valor superior [que] se ha reconocido positivamente» (Jiménez, 2019: 152). Normas que podrían corresponderse con esa categoría serían las prohibiciones de piratería, esclavitud, crímenes de guerra (seria violación de derecho humanitario), crímenes de lesa humanidad, agresión, genocidio, tortura, apartheid (sistemática discriminación racial) y terrorismo (Weatherall, 2015: 205-241). Walker (2016: 314) coincide en que las normas de esta categoría podrían ser las prohibiciones de genocidio, esclavitud, tortura, apartheid y crímenes de guerra. Sin embargo, agrega que también pueden considerarse como tales el derecho a la autodeterminación y la soberanía sobre los recursos naturales.

En ese sentido, se puede entender que no existe un consenso sobre cuáles son en totalidad las normas de ius cogens, lo cual resulta problemático. En efecto, pese a su indudable función como componente sustancial del derecho internacional público, su problema radica en que no tienen - en general - un carácter positivo y sus nor- 
mas se encuentran preponderantemente indeterminadas, reafirmando entonces un carácter ambiguo, lo que puede traer serios inconvenientes de interpretación (MoraCarvajal, 2020: 106-107).

No obstante, la gran virtud del ius cogens en cuanto a la idea del constitucionalismo global es que se erige como «el principal elemento de enlace del conjunto normativo internacional en su momento originario», sobre todo en el ámbito de los «derechos humanos, estando casi todas las normas de ius cogens relacionadas con esta materia» (Jiménez, 2019: 152). Son a nuestro entender —utilizando la terminología de Ferrajoli- una especie de «esfera de lo indecidible» para los Estados, solo mejorables para los derechos humanos.

Precisamente, las normas de ius cogens también son un factor que erosiona la idea clásica de soberanía. Esto se puede ver reflejado incluso con las limitaciones al poder constituyente originario que parecen padecer los Estados hoy en día. En la doctrina constitucional, se encuentra una postura con cada vez más partidarios acerca de límites al poder constituyente originario.

Para explicar de mejor manera la idea, los Estados son libres de dotarse la estructura político-administrativa que estimen más conveniente para su desenvolvimiento y metas. Tal es el principio de no intervención previsto en el artículo 2 de la Carta de las Naciones Unidas. No obstante, el principio de no intervención no supondría una autonomía constitucional absoluta. En efecto, un trabajo de Díez-Picazo (2006: 13) señala en primer lugar que «el principio de no intervención otorga a los Estados un derecho de autonomía constitucional, en el sentido de que no es admisible que sean otros quienes impongan a un Estado las normas constitucionales por las que ha de regirse».

Sin embargo, señala en segundo lugar que «el principio de no intervención no puede entenderse como una absoluta indiferencia del derecho internacional hacia las normas constitucionales adoptadas por los Estados» (Diez-Picazo, 2006: 13). Por ejemplo, la tentativa del poder constituyente de establecer como norma en constitución que la población tendrá privilegios o podrá optar a un cargo público por motivos de raza encontraría serios obstáculos políticos. Del mismo modo, un texto que sistemáticamente vulnere derechos de minorías como los indígenas o migrantes puede, cuanto menos, encontrar óbices para su implementación. En casos así o más graves que violen el derecho internacional de los derechos humanos, cuanto más, se podría justificar una intervención internacional (Grimm, 2015: 109). Claramente, estas situaciones son muy complejas para los Estados y las organizaciones internacionales sobre derechos humanos que ameritan una mayor deliberación.

Prácticas constituyentes de esa índole serían lo que Ferrajoli denomina como política desconstituyente que "puede destruir los derechos. Puede reducir, y no solo poner límites y vínculos a los poderes. Puede muy bien ser desconstituyente en lugar de constituyente» (Ferrajoli, 2018: 72). De manera que los derechos humanos y las pro- 
hibiciones derivadas del ius cogens tienen un rol muy relevante para la política constitucional y fungen como presupuestos para hablar de un constitucionalismo global.

\section{El lugar de los derechos humanos en el constitucionalismo global y la necesidad de llenar el vacío institucional}

\section{Los derechos humanos como punto de partida del constitucionalismo global}

En la literatura se ha escrito con cada vez mayor consideración sobre el constitucionalismo global y su convergencia, pero sobre todo se hace a partir de los derechos humanos, que es su parte más visible. En efecto, ese avance acelerado de los derechos humanos es una tendencia vinculada al «universalismo y posnacionalismo» correspondiente a la erosión de lo particular y nacional en los Estados contemporáneos (Hirschl, 2018: 1-2). Se hace casi común encontrar referencias a la protección de los derechos humanos, entendidos como «valores compartidos de la humanidad, por lo que trascenderían y se posicionarían como elementos universales y supremos» (Jiménez, 2019: 157).

Se destaca que ciertos puntos de encuentro unirían a esta concepción global del constitucionalismo. Peters prefiere llamarlo como valores básicos, en los que se posicionan los derechos humanos que parecen haber «adquirido aceptación universal, como se manifiesta en la ratificación universal de tratados multilaterales relevantes» (Peters, 2018: 6). Los derechos humanos son el punto de partida del constitucionalismo global y la política sobre su implementación global juega un rol central (Gonçalves y Costa, 2015: 4). En palabras de Clavero (2014: 132), «los derechos se consideran la clave que conecta y articula constitucionalismo, especialmente desde un nivel global, el nivel de los derechos humanos como derechos constitucionales replicados y desarrollados por las constituciones de los Estados». De hecho, los derechos humanos implican uno de los compromisos normativos «más profundos» del constitucionalismo global (Shinar, 2019: 17).

Por eso, con base en la universalidad de los derechos humanos como una característica primordial, tales derechos pretenden ser el vehículo que impulsa la propuesta de constitucionalismo global, aquí y allá. Empero, bien es de advertir, como indica Casal (2006: 14), que la afirmación de universalidad de los derechos «no pretende tanto describir una realidad sin fisuras, cuanto subrayar un imperativo ético-jurídico; no se trata de que los derechos humanos rijan efectivamente en todo el mundo, sino de que así debería ser». Peters (2018: 6) hace una advertencia sobre la praxis de ratificar tratados universales en los que se incluyen los derechos humanos, señalando como preocupación que «la ratificación extendida no refleja necesariamente los compromisos genuinos, sino que a menudo es el resultado de desbalances de poder y de maniobras estratégicas». Aun así, los tratados de derechos humanos no dejan de ser 
importantes, así como no dejan de ser importantes las constituciones nacionales a lo interno cuando no se cumplen o se convierten en nominales. Nussbaum (2019: 219), por su parte, señala que los documentos internacionales son «intenciones normativas» que buscan convencer al mundo, pero que no dejan de ser valiosos incluso si no se aplican o no pueden hacerlo, por cuanto «dan fe de un consenso emergente» y se pueden utilizar por parte de activistas en derechos humanos para «ejercer presión» sobre los gobiernos. Un ejemplo de lo señalado por la autora es el movimiento feminista que, tras la Convención sobre la Eliminación de Todas las Formas de Discriminación contra la Mujer de 1979, ha sido un gran medio persuasivo que ha generado conciencia y solidaridad para proteger los derechos humanos de las mujeres que por tanto tiempo se vieron vulnerados. Igual podría suceder con los afrodescendientes, personas con discapacidad, indígenas y demás grupos vulnerables que coexisten en las sociedades heterogéneas.

Así también, considérese que los tratados sobre derechos humanos son un lugar importante en que se plasma el concepto de dignidad humana. Para Habermas (2010: 5), la dignidad humana «solo alcanzó a materializarse en textos de derecho internacional y en las constituciones nacionales recientes hasta después de la Segunda Guerra Mundial». En contraste, continúa el autor, «la noción dignidad humana no apareció como concepto legal ni en las declaraciones clásicas de los derechos humanos del siglo XVIII, ni en las codificaciones del siglo XIX». La importancia de ese concepto se alcanzó no mucho tiempo atrás y eso debido en gran parte a los textos internacionales de derechos humanos que impulsan el constitucionalismo global.

De manera que esa percepción amplia del constitucionalismo supone concebir fenómenos como «la guerra, la opresión, las amenazas al ambiente y la condición de hambre y miseria en que viven miles de personas, no como maldades naturales o como simples injusticias», sino como «violaciones de los principios escritos en esas cartas como normas vinculantes de derecho positivo» (Ferrajoli, 1998: 178). Los derechos humanos son la génesis de lo que se ha dado por denominar constitucionalismo global, que a su vez es una forma parcial de buscar soluciones a los desafíos globales que enfrenta la humanidad.

\section{Algunos problemas de los derechos humanos como vehículo global}

Si bien se señala que los derechos humanos son el punto de partida del constitucionalismo global, existen problemas sobre qué tipo de derechos son lo que impulsan esa propuesta, especialmente cuando se suscitan cuestiones ideológicas. Existen derechos de múltiples categorías y se suele indicar desde una perspectiva teórica general que estos gozan de la característica de interdependencia. Así, es ilustrativo lo que refiere el preámbulo del Pacto Internacional de Derechos Económicos, Sociales y Culturales, al señalar que «no puede realizarse el ideal del ser humano libre, liberado 
del temor y de la miseria, a menos que se creen condiciones que permitan a cada persona gozar de sus derechos económicos, sociales y culturales» $\mathrm{y}$ «tanto como de sus derechos civiles y políticos».

Ahora bien, en la posición del constitucionalismo global se indica por parte de la doctrina que la mayoría de los derechos humanos son más familiares con la primera generación de derechos (civiles y políticos), con énfasis en el derecho a la propiedad privada. En particular, eso se hace notar en el norte global, donde se protege la propiedad de la expropiación, requiriendo fuertes justificaciones para las decisiones que prohíben la propiedad privada en casos particulares (Shinar, 2019: 19).

De hecho, se señala que el constitucionalismo global favorecería la propiedad privada de importantes industrias como un proyecto especialmente neoliberal; los derechos de segunda generación no estarían a la par de los derechos de primera generación porque cuando se incluyen en una constitución deben ser realizados progresivamente dentro de los recursos disponibles (Tushnet, 2019: 33). Entonces, este tipo de apreciaciones chocan con otros razonamientos de la doctrina, como el de Ferrajoli (2018: 87-88), que indica que «los seres humanos están unificados hoy por interés vital común, representado por la necesidad de imponer límites y vínculos garantistas al desarrollo desregulado y salvaje del capitalismo global». Choca porque el constitucionalismo global que piensa Ferrajoli limita la actividad comercial de grandes empresas con el fin de proteger bienes comunes como el medioambiente.

Para Nussbaum (2019: 244-245), tomando en consideración el aspecto de los recursos disponibles para la efectividad de los derechos sociales, señala que «todos los derechos cuestan dinero» y que esa dependencia monetaria es la que hace que todos los derechos sean «económicos y sociales» por extensión, requiriendo "gravar a las personas para disponer de un sistema de libertades, un sistema de contratos y unos tribunales que hagan valer libertades de muchos tipos». Esa es la conocida tesis de Sunstein y Holmes (2011: 99) sobre «el costo de los derechos», que indica que «la protección de los derechos individuales nunca es gratuita, porque siempre presupone la creación y el mantenimiento de relaciones de autoridad». Esto es una dimensión compleja sobre la relación de los derechos de primera y segunda generación.

Por otro lado, se señala con respecto a los derechos de tercera generación que son más asociados con el sur global que con el norte global porque dan lugar a una posible redistribución de la propiedad, lo que a su vez podría poner en riesgo los derechos de propiedad privada (Shinar, 2019: 20). Para otros pensadores, como Cortina (2019: 212), el ideal cosmopolita se muestra «latente en el reconocimiento de los derechos de los refugiados», que es un grupo vulnerable mirado de forma especial por parte de esta corriente, ante fenómenos como las migraciones forzadas. De esta manera, se encuentra una variada cantidad de criterios en ese aspecto que hacen que el componente de los derechos humanos del constitucionalismo global sea vago, pero abierto a imaginar posibles puntos de encuentro. 


\section{El plano institucional en el constitucionalismo global}

Se interpreta que los derechos humanos que han sido reconocidos por los diversos instrumentos internacionales ratificados por los Estados van formando un supuesto cuerpo constitucional internacional, que debería ser y que - ante la ausencia de un conjunto de órganos que los hagan exigibles- todavía no es. Un cuerpo que, según Ferrajoli (1998: 177), «hizo de ellos no solo derechos constitucionales sino supraestatales, transformándolos en límites externos y no simplemente internos de los poderes de los estados». Continúa el autor, «se ha producido un cambio de paradigma en el derecho internacional, transformando un sistema contractual basado en relaciones bilaterales e iguales entre estados soberanos en un verdadero orden jurídico supra estatal». Este es el orden internacional que estaría emergiendo y que no depende exclusivamente en la autodeterminación del Estado (Grimm, 2015: 106-107). Allí, la persona natural es la primera persona legal internacional y el primer miembro de la comunidad global constitucionalizada que se debe considerar en las relaciones sociales (Peters, 2009: 157).

No obstante, dicho orden jurídico supraestatal se encuentra delineado solo mediante una larga parte dogmática o bill of rights, a la cual es necesario teorizar una parte orgánica en que se organice el poder y la forma en que se pueden cumplir los derechos humanos «universales». En palabras de Ferrajoli (2018b: 131), requieren de «las correlativas instituciones de garantía de las cuales depende los derechos proclamados», ya que «en el derecho internacional hacen falta casi todas las garantías de los derechos». En efecto, una adecuada protección de los derechos humanos en el contexto internacional todavía no ha sido alcanzada; se requiere de un largo proceso dialéctico entre los órdenes nacionales e internacionales que permita imaginarlo y materializarlo (Viellechner, 2019: 14). Es decir, «los derechos no son el único componente necesario de los sistemas constitucionales» (Clavero, 2014: 132). Mientras no existan instituciones internacionales de garantía de los derechos humanos, la sociedad internacional continuará siendo lo que Nussbaum (2019: 219) señala como «un ámbito moral de persuasión». Para el constitucionalismo global, las garantías institucionales también son indispensables para que los derechos proclamados se cumplan.

En la comunidad internacional, se indica que se produce «la ausencia de un momento constitucional y un poder constituyente, en el sentido de que los Estados no se han dado una constitución para regular el ordenamiento jurídico internacional y sus instituciones esenciales», por lo cual se trataría de un "proceso evolutivo, siendo la adopción de la Carta de las Naciones Unidas un momento definitivo en este proceso» (Jiménez, 2019: 152). Sin embargo, parece ser difícil implementar de manera global las garantías institucionales. Las estructuras de los Estados nacionales se crearon principalmente con tres poderes: Ejecutivo, Legislativo y Judicial, los cuales tienen funciones y mecanismos de control unos con otros que permiten tener el monopolio del 
aparato coercitivo de la fuerza y garantizar los derechos humanos. Por otro lado, una estructura global «no impone un régimen democrático en particular» (Shinar, 2019: 19), de manera que este ámbito invita a la imaginación constitucional para encontrar posibles puntos de encuentro. Ahora bien, el plano global se hace muy complejo para la imaginación constitucional, por cuanto «un Estado mundial difícilmente podría alcanzar un nivel aceptable de rendición de cuentas ante sus ciudadanos. Sería una empresa demasiado amplia. Las diferencias de cultura y lengua dificultan en exceso la comunicación necesaria, al menos, en el momento actual». Además, vale mencionar que «un Estado mundial sería, además, peligroso», debido a que «no existiría otro recurso equivalente a esa mayor escala» (Nussbaum, 2007: 309).

Otros obstáculos a los que se enfrenta el componente institucional del constitucionalismo global son las ideologías populistas de antiintegración producidas por procesos como el secesionismo, la denuncia de los tratados internacionales y otras formas de disenso. Ejemplos emblemáticos son las situaciones del Brexit en el Reino Unido, la dramática decisión del entonces presidente de los Estados Unidos, Donald Trump, de abandonar el Acuerdo de París, y el retiro de Venezuela de la Corte Interamericana de Derechos Humanos (Hirschl, 2018: 2). Este tipo de fenómenos hace que las promesas institucionales del constitucionalismo global padezcan una tensión y escepticismo (Shinar, 2019: 17). De esa manera, el aspecto institucional del constitucionalismo global con respecto a los derechos humanos es sumamente complicado. Pensar en cómo desarrollar la embrionaria constitución global, a través de la invención de instituciones de alcance global, sería la forma bajo la cual se podría tomar más en serio este fenómeno y afrontar necesidades globales.

\section{Conclusiones}

El constitucionalismo global es un interesante fenómeno que cada vez va adquiriendo mayor importancia en el ámbito académico. La erosión de la soberanía que están padeciendo los Estados de la comunidad internacional es un aspecto clave para comprender esta nueva postura del pensamiento constitucional relacionado con la disciplina del derecho internacional público. Asimismo, los nuevos desafíos que afronta la humanidad en la actualidad no parece que puedan ser resueltos desde los espacios de los Estados nacionales. Como diría Nusbbaum (2012: 23), «al aire le traen sin cuidado las fronteras nacionales». Cosas tan simples como el aire o el agua, que es el líquido de la vida en el planeta Tierra, fungen como bienes comunes vitales que deben protegerse, situación que requiere una respuesta adecuada desde la imaginación constitucional.

Lo que pretende el constitucionalismo global es afianzar un conjunto de regulaciones que afecten a los Estados y que erosione de manera drástica el concepto de soberanía, que cada vez pierde más terreno. Esas regulaciones implican varios ámbi- 
tos, entre ellos el de los derechos humanos. Los derechos humanos son el vehículo de esta postura transformadora del constitucionalismo; a través del carácter universal de los derechos se busca algo así como un lenguaje común y vinculante, en el que las complejas sociedades heterogéneas puedan entenderse para su propio beneficio.

La Declaración Universal de los Derechos Humanos de 1948 y demás acuerdos internacionales que protegen los derechos humanos son el punto de partida de la constitución cosmopolita. Eso se suscita a través de una especie de declaración de derechos de «los pueblos de las Naciones Unidas» como ideal común y no como una aspiración de algún pueblo o nación en particular. Eso parece el argumento más sólido para hablar de un constitucionalismo de tal magnitud, pero no escapa de tener óbices sobre aspectos como qué clase de derechos son los más afines con la propuesta global: ¿derechos civiles, sociales, ambientales, o todos son realizables? ¿Cómo se deben establecer límites a la libertad comercial?

Para reforzar la idea de los derechos humanos y que no sean un simple deseo o esperanza, se requiere de la invención de instituciones encargadas de hacer reales los bienes jurídicos establecidos positivamente en las declaraciones universales de derechos humanos. Sin embargo, eso resulta demasiado complejo por ahora y se enfrenta a múltiples problemas, como los movimientos populistas antiintegración y la falta de imaginación constitucional para pensar nuevas formas de organización apropiadas para los desafíos globales.

Así como surgió el constitucionalismo de los clásicos con los derechos liberales y su diseño institucional de garantías de la libertad individual, luego surgió el constitucionalismo social con los derechos sociales para garantizar mejores condiciones de los grupos más vulnerables. Ambos parecían irrealizables y utópicos para su momento. Para el constitucionalismo global puede ser que llegue el momento en que se produzca un acuerdo mundial con garantías institucionales sobre determinadas materias que afecten a toda la humanidad.

\section{Referencias}

Arendt, Hannah (2006). Sobre la revolución. Trad. de Pedro Bravo. Madrid: Alianza. Atienza, Manuel (1982). «Marx y los derechos humanos». Cuadernos de la Facultad de Derecho, 1: 13-34. Disponible en https://bit.ly/3EYwByt.

ВЕСК, Ulrich (1998a). La sociedad del riesgo: Hacia una nueva modernidad. Madrid: Paidós.

-. (1998b). La invención de lo político. Buenos Aires: Fondo de Cultura Económica.

CASAL, Jesús (2006). Los derechos humanos y su protección: Estudios sobre derechos humanos y derechos fundamentales. Caracas: Universidad Católica Andrés Bello.

Clavero, Bartolomé (2014). Derecho global: Por una historia verosímil de los derechos humanos. Madrid: Trotta. 
Comanducci, Paolo (2010). «Constitucionalización y neoconstitucionalismo». En El canon neoconstitucional (pp. 173-19o). Bogotá: Universidad Externado de Colombia.

Cortina, Adela (2019). Ciudadanos del mundo: Hacia una teoría de la ciudadanía. Madrid: Alianza.

De Vega, Pedro (2007). La reforma constitucional y la problemática del poder constituyente. Madrid: Tecnos.

DíEz-Picazo, Luis (2006). «Límites internacionales al poder constituyente». Revista Española de Derecho Constitucional, 76: 9-32. Disponible en https://bit.ly/3m5J2Bc. Dippel, Horst (2009). Constitucionalismo moderno. Madrid: Marcial Pons.

Ferrajoli, Luigi (1998). «Más allá de la soberanía y ciudadanía: Un constitucionalismo global». Isonomía, 9: 173-184. Disponible en https://bit.ly/3pZldMn.

-. (2004). Derechos y garantías: La ley del más débil. Madrid: Trotta.

-. (2007). «Sobre los derechos fundamentales». En Teoría del neoconstitucionalismo (pp. 71-89). Madrid: Trotta.

-. (2011). Poderes salvajes: La crisis de la democracia constitucional. Madrid: Trotta.

-. (2018a). Constitucionalismo más allá del Estado. Madrid: Trotta.

-. (2018b). Libertad y propiedad: Por un constitucionalismo de derecho privado. Lima: Palestra.

Fioravanti, Murizio (2014). Constitucionalismo: Experiencias históricas y tendencias actuales. Madrid: Trotta.

García-Pelayo, Manuel (1977). Las transformaciones del Estado contemporáneo. Madrid: Alianza.

GonçALves, Guilherme y Sérgio Costa (2015). «The global constitutionalization of human rights: Overcoming contemporary injustices or juridifying old asymmetries?». Current Sociology, 64 (2): 1-21. DOI: $10.1177 / 0011392115614791$.

Grimm, Dieter (2015). Sovereignty: The origin and future of a political concept. Nueva York: Columbia University Press.

Guastini, Ricardo (2016). Estudios de teoría constitucional. Xicoco: Universidad Autónoma de México.

HäBERLE, Peter (2003). La garantía del contenido esencial de los derechos fundamentales. Madrid: Dykinson.

Habermas, Jürgen (2008). «The constitutionalization of international law and the legitimation problems of constitution for world society». Constellations, 15 (4): 444-455. DOI: 10.1111/j.1467-8675.2008.00510.x.

-. (2010). «El concepto de dignidad humana y la utopía realista de los derechos humanos». Diánoia, 64: 3-25. DOI: 10.21898/dia.v55i64.218.

Hirschl, Ran (2018). "Opting out of "global constitutionalism"». Law \& Ethics of Human Rights, 12 (1): 1-36. DOI: 10.1515/lehr-2018-0003. 
Jellinek, Georg (2004). Teoría general del Estado. Ciudad de México: Fondo de Cultura Económica.

JIMÉNEZ, Ángel (2019). «El constitucionalismo global: ¿Neologismo necesario o mera cacofonía?». Revista Española de Derecho Constitucional, 117: 139-166. Disponible en https://bit.ly/3yopcWV.

Kyмlicka, Will (1996). Ciudadanía multicultural: Una teoría liberal de los derechos de las minorías. Madrid: Paidós.

Montesquieu (1986). El espíritu de las leyes. Tomo 1. Madrid: Librería General de Victoriano Suárez.

Mora-Carvajal, David (2020). «El constitucionalismo global: ¿Oportunidad para un derecho internacional más unitario y coherente?». Revista Derecho del Estado, 45: 101-119. DOI: 10.18601/01229893.n45.04.

Neves, Marcelo (2004). «La fuerza simbólica de los derechos humanos». Doxa, 27: 143-180. DOI: 10.14198/DOXA2004.27.06.

Nussbaum, Martha (2007). Las fronteras de la justicia: Consideraciones sobre la exclusión. Madrid: Paidós.

-. (2012) Los límites del patriotismo: Identidad, pertenencia y «ciudadanía mundial». Madrid: Paidós.

-. (2019). The cosmopolitan tradition: a noble but flawed ideal. Cambridge: The Belknap Press of Harvard University Press.

O'Donnell, Guillermo (2004). «Accountability horizontal: La institucionalización legal de la desconfianza política». Revista Española de Ciencia Política, 11: 11-31. Disponible en https://bit.ly/3yo69f.

PÉREZ, Javier (2003). Curso de derecho constitucional. Madrid: Marcial Pons.

Peters, Anne (2009). «Membership in the global constitutional community». En The constitutionalization of international law. Oxford: Oxford University Press. DOI: 10.1093/acprof:0so/9780199543427.003.0005.

-. (2018) «Los méritos del constitucionalismo global». Derecho del Estado, 40: 3-20. DOI: 10.18601/01229893.n40.01.

PISARELLO, Gerardo (2007). Los derechos sociales y sus garantías: Elementos para su reconstrucción. Madrid: Trotta.

SAGUÉs, Néstor (2009). «Notas sobre el poder constituyente irregular». Anuario de Derecho Constitucional Latinoamericano, 15: 151-163. Disponible en https://bit. ly/3IRWB11.

SHINAR, Adam (2019). "The ideologies of global constitutionalism». Global Constitutionalism, 8 (1): 12-28. DOI: $10.1017 / S_{20} 04538171800031 \mathrm{X}$.

Somek, Alexander (2014). The cosmopolitan constitution. Oxford: Oxford University Press.

Sunstein, Cass y Stephen Holmes (2011). El costo de los derechos, por qué la libertad depende de los impuestos. Buenos Aires: Siglo Veintiuno. 
TushnET, Mark (2019). «The globalisation of constitutional law as a weakly neo-liberal project». Global Constitutionalism, 8 (1): 29-39. DOI: 10.1017/S204538171800028X. VIELLECHNER, Lars (2019). «The transnational dimension of constitutional rights: Framing and taming 'private' governance beyond the state». Global Constitutionalism, 8 (3): 1-23. DOI: https://doi.org/10.1017/S2045381719000194.

Walker, Neil (2016). «Postnational constitutionalism and the challenge of contested multilateralism». Global Constitutionalism, 5 (3): 309-319. DOI: 10.1017/ S2045381716000174.

Weatherall, Thomas (2015). Ius cogens, international law and social contract. Londres: Cambridge University Press.

Wiener, Antje, Anthony Lang, James Tully, Miguel Maduro y Mattias Kumm (2012). «Global constitutionalism: Human rights, democracy and the rule of law». Global Constitutionalism, 1 (1): 1-15. DOI: 10.1017/S2045381711000098.

Zagrebelsky, Gustavo (2011). Derecho dúctil. Madrid: Trotta.

\section{Sobre el autor}

Angello Javier Peña Barrios es abogado summa cum laude por la Universidad de Los Andes, Venezuela. Investigador adscrito al Grupo de Investigación Robert Von Möhl de la Universidad de Los Andes. Monitor de la Red Universitaria de Amnistía Internacional Venezuela en la Universidad de Los Andes. Su correo electrónico es angellojavierpb@gmail.com. (D) https://orcid.org/00oo-0003-2381-0324. 
